TITLE: RESIDUAL STRESS, MECHANICAL BEHAVIOR AND ELECTRICAL PROPERTIES OF COPPER/NIOBIUM THIN-FILM MULTILAYERS

AUTHOR(S): A. J. Griffin, Jr., J. D. Embury, M. F. Hundley, T. R. Jervis, H. H. Kung, W. K. Scarborough, K. C. Walter, J. Wood and M. Nastasi

SUBMITTED TO:

Proceedings of the Spring 1995 Materials Research Society Meeting San Francisco, CA
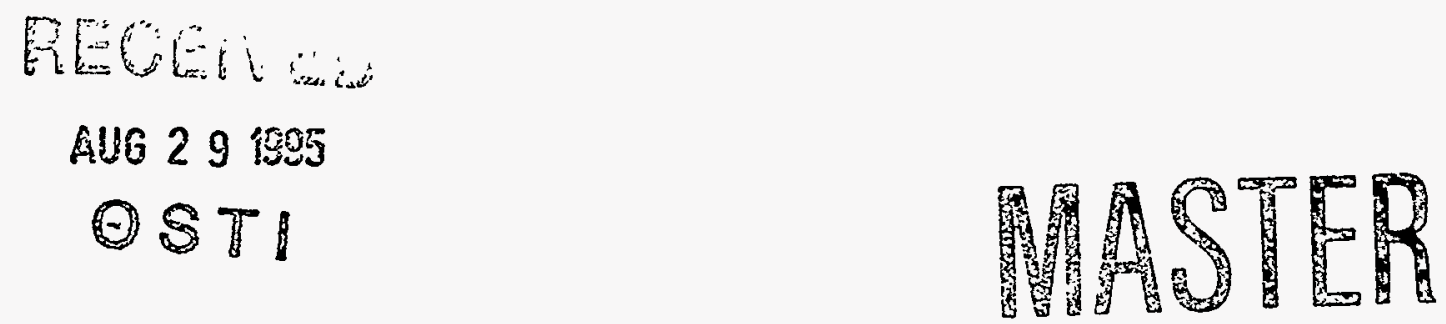

By acceptance of this article. the publisher recognizes that the U.S Government retains a nonexclusive. royalty-Iree license to publish or reproduce the published form of this contribution. or to allow others to do so, for U.S Government purposes

The Los Alamos National Laboratory requests that the publisher identily this article as work performed under the auspices of the U S Department of Energy
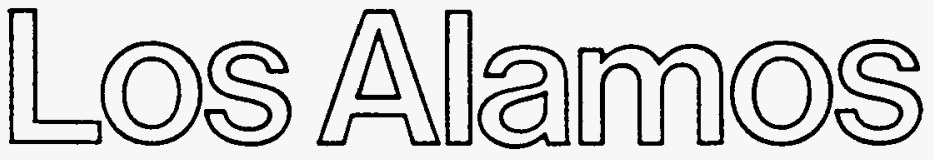

Los Alamos National Laboratory Los Alamos,New Mexico 87545 


\section{DISCLAIMER}

Portions of this document may be illegible in electronic image products. Images are produced from the best available original document. 


\title{
RESIDUAL STRESS, MECHANICAL BEHAVIOR AND ELECTRICAL PROPERTIES OF Cu/Nb THIN-FILM MULTILAYERS
}

\author{
A. J. GRIFFIN, JR.,* J. D. EMBURY,** M. F. HUNDLEY,* T. R. JERVIS,* H. H. \\ KUNG,* W. K. SCARBOROUGH,* K. C. WALTER,* J. WOOD** AND M. NASTASI* \\ *Los Alamos National Laboratory, Los Alamos, NM 87545 \\ **McMaster University, Ontario, Canada
}

\begin{abstract}
The effect of compositional wavelength on the residual stress, electrical resistivities and mechanical properties of $\mathrm{Cu} / \mathrm{Nb}$ thin-film multilayers sputtered onto single-crystal $\mathrm{Si}$ substrates was evaluated. Electrical resistivities were measured down to $4^{\circ} \mathrm{K}$ using a standard four-point probe measurement system. A differential specimen-curvature technique was used to determine residual stress, and a mechanical-properties microprobe was employed to obtain hardness and elastic modulus. Characterization techniques included profilometry, Ion-Beam Analysis (IBA) and Transmission Electron Microscopy (TEM). The hardness of the $\mathrm{Cu}-\mathrm{Nb}$ multilayers increased with decreasing compositional wavelength so that the layered structures had hardness values in excess of either of the constituents and the hardness predicted by the rule of mixtures. A peak in the net residual compressive stress of the multilayers was observed at a compositional wavelength of 100 $\mathrm{nm}$. No resistivity plateau was observed within the composition wavelength range studied.
\end{abstract}

\section{INTRODUCTION}

Copper-niobium microcomposites have been studied over the last three decades because of the exceptional combinations of high strength and excellent thermal and electrical conductivity that can be obtained and optimized for a variety of applications. ${ }^{1 \cdot 3}$ Much of the work centered initially on the production and evaluation of in-situ composites that were formed by successive wire drawing or rolling of $\mathrm{Cu}-\mathrm{Nb}\left(10-30\right.$ volume percent) alloys. ${ }^{4,5}$ The microstructures of these in-situ composites were thus composed of $\mathrm{Nb}$ filaments or platelets within a $\mathrm{Cu}$ matrix - a result of the insolubility of $\mathrm{Nb}$ and the presence of $\mathrm{Nb}$ dendrites within the as-cast $\mathrm{Cu}-\mathrm{Nb}$ alloy starting materials. ${ }^{6}$ However, a true $\mathrm{Cu}-\mathrm{Nb}$ microlaminate composite consisting of alternating, uniformly parallel $\mathrm{Cu}$ and $\mathrm{Nb}$ films of known thickness can be easily produced by either evaporation or sputtering. The properties of $\mathrm{Cu}-\mathrm{Nb}$ thin-film multilayer structures lend themselves well to being evaluated as a function of compositional wavelength, volume fraction and film microstructure instead of the average dendrite, filament or platelet spacing.

Compositionally modulated thin-film structures can exhibit strengths that are in excess of that predicted by the rule of mixtures. ${ }^{7,8}$ The strength can be tailored to suit a variety of applications by varying the thickness of the individual component films. $\mathrm{Cu}-\mathrm{Nb}$ thin-film multilayer structures can therefore be used as high-strength thermal and electrical conductors as well as high-temperature, wear-resistant conductive coatings. Although previous investigations have been performed on $\mathrm{Cu}-\mathrm{Nb}$ multilayers, these have involved phenomena of superconductivity as well as the anomalies exhibited in both the phonon dispersion curves and the folded Brillouin zones.,10 This research is the first in a series of investigations designed to look at the effect of deposition conditions, volume fraction and composition wavelength on various properties of $\mathrm{Cu}-\mathrm{Nb}$ thin-film multilayer structures. Specifically, this paper presents preliminary results on the effect of compositional wavelength on the residual stress, mechanical behavior and electrical properties of $\mathrm{Cu}-\mathrm{Nb}$ multilayers. 
Substrates were cut from $0.4 \mathrm{~mm}$ thick partially-oxidized (200-250 nm oxide thickness) single-crystal $\mathrm{Si}\{100\}$ wafers using a wafer-dicing machine. As-cut substrate dimensions were $10 \times 10 \mathrm{~mm}$ for TEM, nanoindentation, profilometry and IBA specimens; $4 \times 20 \mathrm{~mm}$ for the resistivity specimens and $5 \times 38 \mathrm{~mm}$ for the residual stress-measurement specimens. Specimens were cleaned with an acetone-methanol-water wash sequence followed by a 1 minute dip in a 20\%HF solution and a final rinse in deionized water. Carbon and molybdenum substrates were also prepared for use as IBA substrates by simply cutting $C$ and Mo into $10 \times 10 \mathrm{~mm}$ squares. A deposition run consisted of four resistivity, two stress-measurement and four square specimens as well as one $\mathrm{C}$ and one Mo specimen.

All of the depositions were made using a de magnetron sputterer. The purity of the $\mathrm{Cu}$ and $\mathrm{Nb}$ targets were $99.999 \%$ and $99.95 \%$, respectively. The base pressure after specimen loading was between $9.0 \times 10^{-9}$ and $2.1 \times 10^{-8}$ Torr. Prior to each multilayer deposition run, the targets were sputter-cleaned for a few minutes. The multilayer depositions were computer-controlled, and each deposition sequence consisted of the following: a 5 minute pump-down, opening of the $\mathrm{Ar}$ mass-flow controller set at $28 \mathrm{cc} \mathrm{min}-1$ and a working pressure of $2 \mathrm{mTorr}$, a stabilization time of approximately 3 minutes, application of $300 \mathrm{~W}$ of power to the target, a command to turn and hold the specimens towards the sputtering target for the predetermined deposition time and the removal of power from the target. The layering sequence was always $\mathrm{Nb}$ then $\mathrm{Cu}$. Deposition rates and film densities were determined through a combination of profilometry and IBA techniques. The total thickness for each composition wavelength studied was $1000 \mathrm{~nm}$ and the volume fraction was kept constant at $50 \%$.

Characterization of the as-deposited multilayers was performed using TEM and IBA techniques. TEM cross-sections were prepared using standard cutting, polishing, dimpling and low-angle ion-milling procedures. Cross-sections were examined using conventional and high-resolution TEM on a Phillips CM30ST operating at $300 \mathrm{kV}$. Standard Ion-Backscattering Spectra (IBS) were obtained using $2 \mathrm{MeV} \mathrm{He}$ ions and a scattering angle of $166^{\circ}$ in order to obtain the areal atomic density and thickness of each multilayer. The atomic percentage of $O$ was determined using $7.6 \mathrm{MeV} \mathrm{He}{ }^{++}$ions because of the enhanced non-Rutherford scattering cross-section for $\mathrm{O}$ at this energy; ${ }^{11}$ in this case, however, the multilayers evaluated were those deposited on Mo. Hydrogen content was measured using Forward Recoil Elastic Spectrometry (FRES) with $3.55 \mathrm{MeV} \mathrm{He}^{+}$ions and a scattering angle of $30^{\circ}$.

A Nanoindenter ${ }^{\otimes} \mathrm{I}$ was used in all of the indentation experiments. The nominal indentation depth was $100 \mathrm{~nm}$. Electrical resistivity measurements from 4 to $300 \mathrm{~K}$ were done using a standard 4-point probe technique. Residual stress measurements were performed using a differential specimen-curvature technique. ${ }^{12,13}$ The net residual stress was determined by measuring specimen curvature both with and without the multilayer films, and then calculating the stress from the Stoney equation ${ }^{14}$ using the difference between their radii of curvature. ${ }^{12.13}$

\section{RESULTS AND DISCUSSION}

Figures $1 \mathrm{a}$ and $1 \mathrm{~b}$ are the IBS and FRES spectra, respectively, for the 5 bilayer $(100 \mathrm{~nm} / 100 \mathrm{~nm}) \mathrm{Cu}-\mathrm{Nb}$ structure. The IBS spectrum includes the actual data and its appropriate simulation, while the FRES spectrum displays the simulation alone, for clarity. Each peak in the IBS spectrum is the superposition of signals from $\mathrm{Cu}$ and $\mathrm{Nb}$ in a bilayer pair. The modulation is a result of specimen geometry, film thickness and the difference between the stopping powers and kinematic factors of $\mathrm{Cu}$ and $\mathrm{Nb}$. Simulations of IBA spectra were performed using RUMP. ${ }^{15}$ The IBA thickness of each layer is calculated from the measured areal atomic density using the densities of $\mathrm{Cu}$ and $\mathrm{Nb}$. The densities of $\mathrm{Cu}$ and $\mathrm{Nb}$ were obtained from a combination of profilometry and IBS measurements made on individual $\mathrm{Cu}$ and $\mathrm{Nb}$ films. The sharp peak near channel 490 in the FRES spectrum corresponds to the signal from a few monolayers of water on the surface of the first Cu layer. Subsequent alternating increases and decreases in the $\mathrm{H}$ signals can be attributed to 


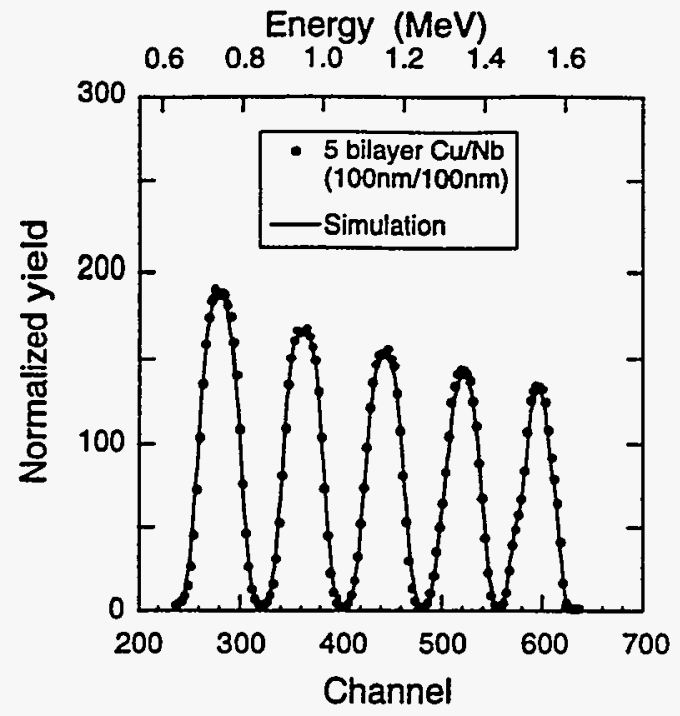

Figure 1a: RBS spectrum and simulation; $2 \mathrm{MeV} \mathrm{He}{ }^{+}$ions; $0^{\circ}$ tilt.

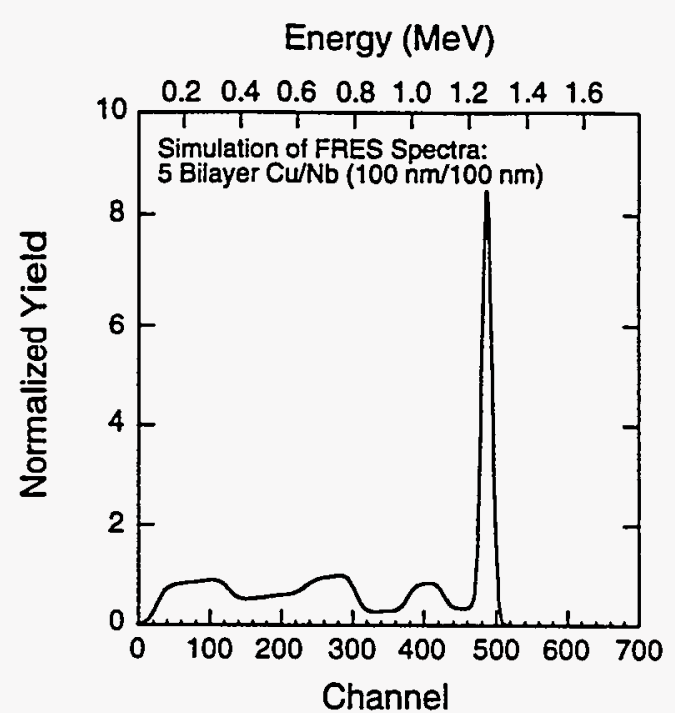

Figure 1b: FRES simulation. 3.55 $\mathrm{MeV} \mathrm{He}^{+}$ions; $75^{\circ}$ tilt.

the higher affinity $\mathrm{Nb}$ has for $\mathrm{H}$ relative to $\mathrm{Cu}$. It should be emphasized that, because of the $75^{\circ}$ specimen tilt and the concomitant increase in apparent path length, only the signals coming from the first three bilayers appear to be discerned in the spectrum. The simulation of the FRES spectrum was used to determine the atomic concentration of $\mathrm{H}$ in each layer.

Table I lists the compositional analysis of the 5 bilayer $\mathrm{Cu}-\mathrm{Nb}$ structure. Table I was obtained by combining the profilometry and IBS simulation data for $\mathrm{Cu}$ and $\mathrm{Nb}$ films with the IBS and FRES simulations obtained on the multilayer structures. A relative error of approximately $10 \%$ may exist in the listed thickness and composition values. As mentioned previously, the $\mathrm{H}$ content is higher in the $\mathrm{Nb}$ because of the affinity $\mathrm{Nb}$ has for $\mathrm{H}$. The decreased $\mathrm{H}$ content in the outer layers results from the ability of the $\mathrm{H}$ to diffuse away or out from the surface both during and after the deposition sequences, thereby leading to a $\mathrm{H}$ concentration gradient across the entire multilayer. The actual densities of $\mathrm{Cu}$ and $\mathrm{Nb}$ were 8.91 and $8.65 \mathrm{~g}^{\circ} \mathrm{cm}^{-3}$, respectively, which were within approximately $-0.1 \%$ of the theoretical density for the former and $+0.8 \%$ of the theoretical density for the latter. Oxygen was not detected within any of the $\mathrm{Cu}, \mathrm{Nb}$ or $\mathrm{Cu}-\mathrm{Nb}$ multilayer films.

Table I: Characterization Results for a 5-Bilayer Cu-Nb Thin-film Structure

\begin{tabular}{ccccc} 
Layer & atomic \% Cu & atomic \% Nb & atomic \% & Thickness, $\mathrm{nm}$ \\
\hline $1-\mathrm{Cu}$ & 99.7 & 0 & 0.3 & 88 \\
$2-\mathrm{Nb}$ & 0 & 98.9 & 1.1 & 77 \\
$3-\mathrm{Cu}$ & 99.7 & 0 & 0.3 & 88 \\
$4-\mathrm{Nb}$ & 0 & 98.3 & 1.7 & 80 \\
$5-\mathrm{Cu}$ & 99.1 & 0 & 0.9 & 88 \\
$6-\mathrm{Nb}$ & 0 & 97.5 & 2.5 & 85 \\
$7-\mathrm{Cu}$ & 98.5 & 0 & 1.5 & 88 \\
$8-\mathrm{Nb}$ & 0 & 97.0 & 3.0 & 90 \\
$9-\mathrm{Cu}$ & 98.5 & 0 & 1.5 & 92 \\
$10-\mathrm{Nb}$ & 0 & 97.0 & 3.0 & 88
\end{tabular}

A TEM cross-section of the 5 bilayer $\mathrm{Cu}-\mathrm{Nb}$ structure is shown in Figure 2. The individual layers are relatively smooth and separated by sharp interfaces. High-resolution TEM verified these observations. A selected-area diffraction (SAD) pattern revealed a strong texture in each of the $\mathrm{Nb}$ and $\mathrm{Cu}$ layers. The cross-section texture was $\mathrm{Si}<110>\|\mathrm{Nb}<111>\| \mathrm{Cu}<110\rangle$. Texturing is not uncommon in sputtered $\mathrm{Cu}$ or $\mathrm{Nb}$ thin films deposited on $\mathrm{Si}$. However, strains associated with growth textures lead to a net residual stress, as was seen in the specimen-curvature measurements. 


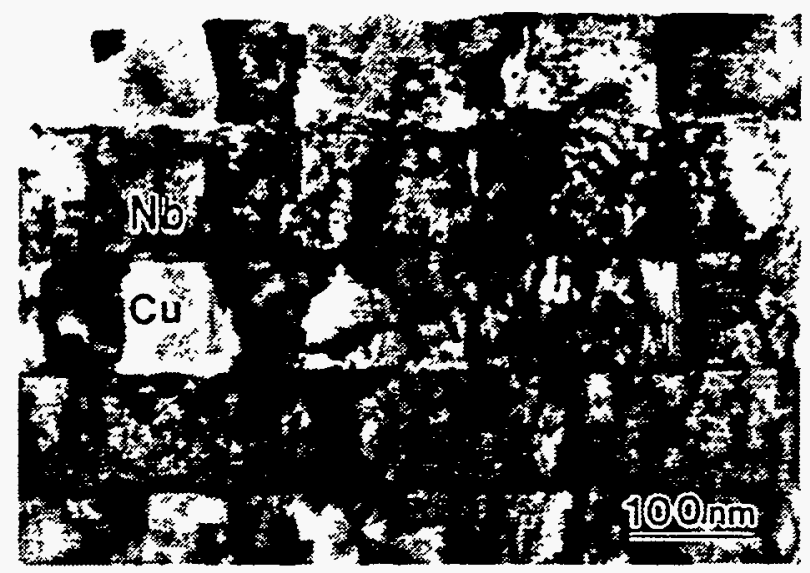

Figure 2: TEM cross-section of the $\mathrm{Cu}(100 \mathrm{~nm}) / \mathrm{Nb}(100 \mathrm{~nm})$ multilayer. The $\mathrm{Cu}$ layer is on top and each underlying layer alternates between $\mathrm{Nb}$ and $\mathrm{Cu}$.

The hardness as a function of reciprocal layer thickness $(\lambda / 2)$ for an indentation depth of $100 \mathrm{~nm}$ is shown in Figure 3. An increase in the hardness of $100 \%$ is observed as the compositional wavelength is decreased from 1000 to $10 \mathrm{~nm}$. Perhaps most interesting is the $100 \%$ increase in the hardness over the value predicted by the rule of mixtures, which is represented by the solid data point on the left axis (the rule of mixtures value was calculated using hardness measurements made on $1000 \mathrm{~nm}$ thick $\mathrm{Cu}$ and $\mathrm{Nb}$ layers). The observed hardness increase over that predicted by the rule of mixtures is not surprising when one considers the strengthening mechanism first proposed by Koehler ${ }^{7}$ and later demonstrated by Lehoczky ${ }^{8}$. Strengthening can occur if the two materials composing a multilayer structure have different dislocation-line energies, so that the termination of dislocation motion in the low dislocation-energy material is favored over dislocation propagation into the high dislocation-line energy material. ${ }^{7,8}$ Moreover, strengthening is enhanced if the layers are made thin enough so as to inhibit the operation of Frank-Read sources. ${ }^{7}$ As a result, the $\mathrm{Cu}-\mathrm{Nb}$ multilayers were harder than either of the individual components. The average elastic modulus of the multilayer structures was $152 \pm 20 \mathrm{GPa}$, which was equal to the rule of mixtures value. No anomalies in the elastic modulus or the hardness were observed.

The residual stress in $1000 \mathrm{~nm} \mathrm{Cu}$ and $1000 \mathrm{~nm} \mathrm{Nb}$ films was +200 and $-16 \mathrm{MPa}$, respectively. Consequently, because tensile stresses are often associated with free volume at grain boundaries and compressive stresses are attributed to atomic peening, ${ }^{16}$ the calculated $\mathrm{Cu}$ and $\mathrm{Nb}$ film densities are substantiated. All of the multilayer films had net compressive stresses. However, a peak in the compressive stress $(145 \mathrm{MPa})$, which was approximately 5 times greater than the average stress of the other multilayers, was observed in the $100 \mathrm{~nm} / 100 \mathrm{~nm} \mathrm{Cu} / \mathrm{Nb}$ multilayer structure. This phenomenon has also been observed in Au-Ni multilayers. ${ }^{17}$ Although the residual stresses in $\mathrm{Cu}, \mathrm{Nb}$ and multilayer $\mathrm{Cu}-\mathrm{Nb}$ films have been determined, the interaction between the intrinsic and thermal stresses of individual layers and their overall effect on the net stress of multilayers is not yet fully understood. Consequently, the parameters that govern the location and the magnitude of the peak in compressive stress will require further study.

The longitudinal electrical resistivity as a function of temperature for the different multilayer structures is shown in Figure 4. The sharp drop-offs at or near $10 \mathrm{~K}$ are a result of the superconductivity of the $\mathrm{Nb}$ layers. For temperatures between 10 and $300 \mathrm{~K}$, the resistivity vs. temperature curve for the single bilayer structure matches that predicted by the rule of mixtures. However, an increase in the number of bilayers leads to resistivity values greater than those predicted by the rule of mixtures - a result of interfacial scattering. An observed decrease in the critical temperature for superconductivity with smaller layer thickness may also be caused by the increased number of interfaces. A resistivity plateau such as that observed by Skomski et al. ${ }^{18}$ in $\mathrm{Co}-\mathrm{Pd}$ and $\mathrm{Pd}-\mathrm{Au}$ multilayers was not observed within the compositional wavelength range studied. In order for the plateau to be viewed and therefore differentiated from the resistivity behavior predicted from size-interface theory, the compositional wavelengths must be further reduced. 


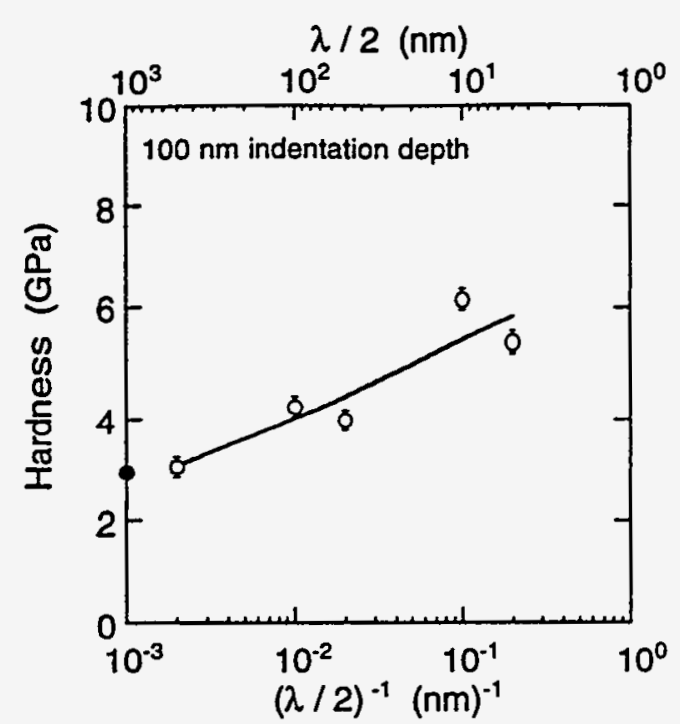

Figure 3: Hardness as a function of reciprocal layer thickness $(\lambda / 2)$.

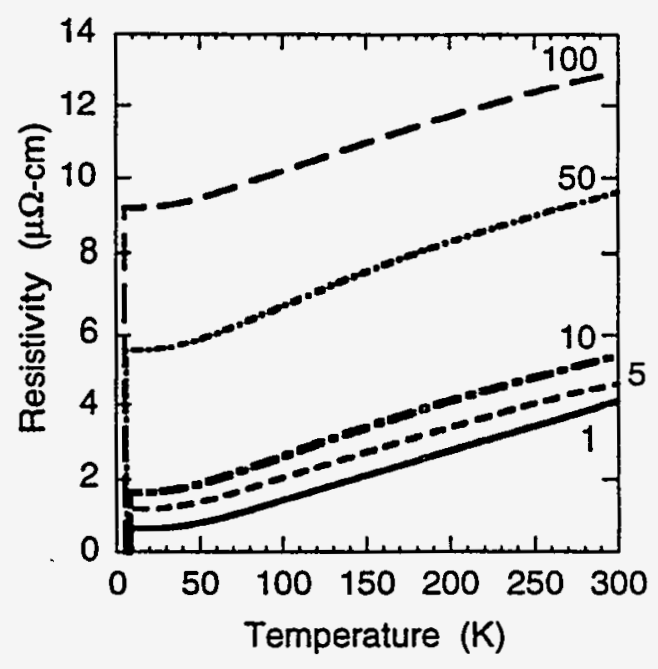

Figure 4: Resistivity as a function of temperature and number of bilayers.

\section{CONCLUSIONS}

The effect of compositional wavelength on the residual stress, mechanical behavior and electrical properties of $\mathrm{Cu}-\mathrm{Nb}$ multilayers was determined. The wavelength range evaluated was between 10 and $1000 \mathrm{~nm}$ and the volume fraction of each constituent was kept constant at $50 \%$. TEM micrographs revealed that the multilayers were relatively smooth and had sharp interfaces. SAD patterns demonstrated strong texturing within both the $\mathrm{Cu}$ and the $\mathrm{Nb}$ layers. The films were oxygen-free, but contained between 0 and 3 atomic percent $H$. The hardness increased as the compositional wavelength was decreased; this increase in hardness was approximately $100 \%$ over the hardness value predicted by the rule of mixtures. No anomalies in the elastic modulus were observed, and the average modulus of the $\mathrm{Cu}-\mathrm{Nb}$ multilayers was approximately $150 \mathrm{GPa}$; equal to that predicted by the rule of mixtures. Each of the $\mathrm{Cu}-\mathrm{Nb}$ multilayers had a net residual compressive stress. However, a peak in the compressive stress as a function of compositional wavelength was observed. The electrical resistivities of the multilayers increased with decreasing compositional wavelength, a result of the greater number of interfaces present. No plateaus in either the electrical resistivity or the hardness as a function of compositional wavelength were observed. However, the plateaus may be revealed if the compositional wavelengths of these multilayers are further reduced. An explanation for the peak in the compressive stress will require further study of the interaction between compositional wavelength and the intrinsic and thermal stresses of strongly textured $\mathrm{Cu}-\mathrm{Nb}$ multilayers.

\section{ACKNOWLEDGMENTS}

The authors would like to thank Cynthia A. Volkert of AT\&T Bell Laboratories and Stephen R. Foltyn of Los Alamos National Laboratory for their help in developing the differential specimen-curvature technique. In addition, the assistance of C. R. Evans, M. G. Hollander, P. D. Kodali, C. J. Maggiore, T. H. Pierce, R. F. Rockage and J. R. Tesmer, all from Los Alamos National Laboratory, is also greatly appreciated. This research was supported in part by the DOE Office of Basic Energy Sciences/Advanced Energy Projects. 


\section{REFERENCES}

1. J. D. Verhoeven, H. L. Downing, L. S. Chumbley and E. D. Gibson, J. Appl. Phys., 65, 1293 (1989).

2. K. T. Chiang, K. J. Kallenborn, J. L. Yuen and N. E. Paton, Mater. Sci. and Eng., A156, 85 (1992).

3. P. Liu, S. Bahadur and J. D. Verhoeven, Wear, 166, 133 (1993).

4. S. Foner, E. J. McNiff, Jr., B. B. Schwartz and R. Roberge, Appl. Phys. Lett., 31, 853 (1977).

5. J. P. Harbison and J. Bevk, J. Appl. Phys., 48, 5180 (1977).

6. P. D. Krotz, J. A. Flint, J. L. Yuen and N. E. Paton, Mater. Sci. and Eng., A149, 225 (1992).

7. J. S. Koehler, Phys. Rev. B, 2, 547 (1970).

8. S. L. Lehoczky, J. Appl. Phys., 49, 5479 (1978).

9. G. Zheng, Y. Kitaoka, Y. Oda, Y. Kohori, K. Asayama, Y. Obi, H. Fujimori and R. Aoki, Physica B, 165\&166 481 (1990).

10. X. Zhang, H. Xia and A. Hu, Phys. Stat. Sol. B, 155, 137 (1989).

11. Handbook of Modern Ion Beam Analysis, edited by J. R. Tesmer and M. Nastasi, (MRS, Pittsburgh, in press).

12. W. D. Nix, Met. Trans., 20A, 2217 (1989).

13. C. A. Volkert, J. Appl. Phys., 70, 3521 (1991).

14. G. G. Stoney, Proc. Roy. Soc. (London), A82, 172 (1909).

15. L. R. Doolittle, Ph.D. Thesis (Cornell University, Ithaca, New York, 1987).

16. . H. Windischmann, J. Vac. Sci. Technol., A9, 2431 (1991).

17. S. P. Baker and W. D. Nix, J. Mater. Res., 9, 3145 (1994).

18. R. Skomski, M. Enrech and J. M. D. Coey, Nanostruct. Mater., 1, 337 (1992).

\section{DISCLAIMER}

This report was prepared as an account of work sponsored by an agency of the United States Government. Neither the United States Governolied, or assumes any legal liability or responsiThes, makes any warranty, express or implied, or any information, apparatus, product, bility for the accuracy, completeness, or usefulnould not infringe privately owne name, trademark, process disclosed, or represents that its use wroct, process, or service by trade namement, recomproce herein to any specific commercial predsarily constitute or imply its end thereof. The views ence herein to an otherwise does not necessarily Government or any agency theres. Those of the mendation, or favoring by the United States do not and opinions of authors expres agency thereof. United States Government or any 